\title{
DOE LLW CLASSIFICATION RATIONALE
}

A. Y. Flores

September 16, 1991

Idaho National Engineering Laboratory EG\&G Idaho, Inc. Idaho Falls, ID

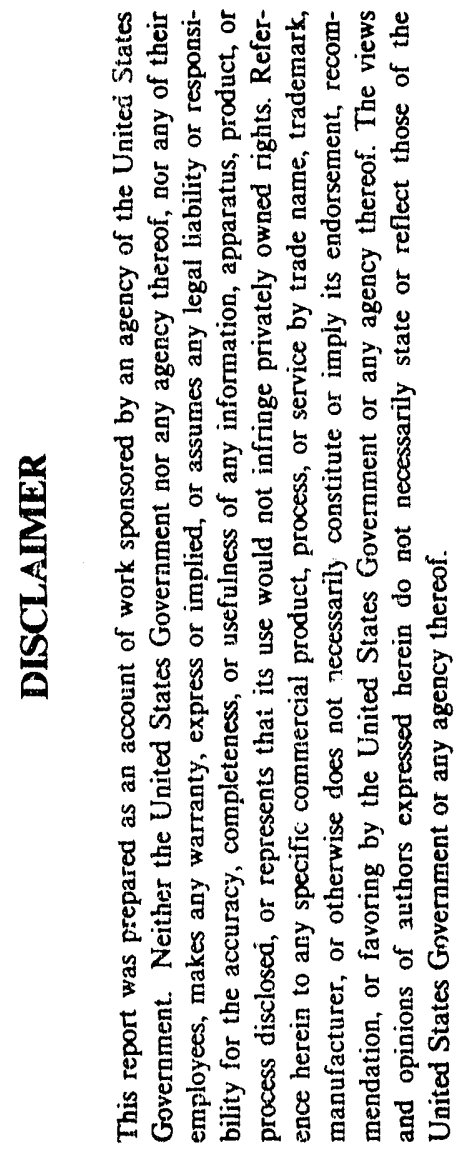

\section{Prepared by the \\ Radioactive Waste Technical Support Program for the \\ U. S. Department of Energy \\ Office of Environmental \\ Restoration and Waste Management \\ Under DOE Contract DE-AC07-76ID01570}




\section{DOE LLW CLASSIFICATION RATIONALE}

\section{EXECUTIVE SUMMARY}

In 1986, the Defense Low-Level Waste Management Program (DLLWMP) began rewriting DOE Order 5820.2, Chapter III, "Low-Level Waste." Department of Energy (DOE)-Headquarters (HQ) expanded this initiative and issued formal direction to rewrite the entire order.

In early 1987, DOE began research to establish a low-level radioactive waste (LLW) classification system. DOE set up a working group to draft a prescriptive or a performance objective-oriented revision of the LLW chapter of DOE Order 5820.2. The simplest option was to adopt the Nuclear Regulatory Commission's (NRC) 10 CFR 61 classification system, based on concentration of indicator nuclides and specific concentration limits for troublesome species. August 1987 was the goal for completing a working draft of the revised LLW chapter.

The consensus at preliminary meetings was that DOE should follow the NRC 10 CFR 61 classification system as closely as possible. The goal in adopting this system was that DOE should modify the NRC waste classification system according to the DOE system approach, existing policy, and special needs. Also, DOE should adopt an intruder approach, the classification system should be cost effective, and it should reduce the burden placed on the waste disposal operators. The DLLWMP was interested in establishing Class I, II, and III 1 imits based on intruder protection purposes only.

DOE site operators met in May 1987 to review the draft DOE approach to waste classification and to establish overall.performance objectives. In calculating draft DOE limits, the same scenarios and assumptions identified by the NRC for 10 CFR 61 were used, with two exceptions. The exceptions were (a) the DOE dose verformance objectives were to be $100 \mathrm{mrem} / \mathrm{yr}$ effective dose equivalent (EDE) for continuous exposures and $500 \mathrm{mrem} / \mathrm{yr}$ EDE for short-term exposures, and (b) the DOE internal dose factors were to be based on International Commission on Radiation Protection (ICRP)-30, Limits for Intakes of Radionuclides by Workers. NRC used ICRP-2, Radiation Protection, Report of Committee II On Permissible Dose of Internal Radiation, for its calculations. DOE adopted the more recent ICRP-30 and ICRP-48, Metabolism of Plutonium and Related Elements, as the basis for all internal dose calculations. These changes accounted for the majority of the differences between the DOE and NRC waste classification limits.

A waste classification table was developed at Pacific Northwest Labo: atory and sent to the sites for review and comment. In general, comments on the waste classification table in Appendix A, Chapter III, of the Order were (a) the limits were lower than the NRC 1 imits, and (b) certain radionuclides (iodine-129, radium-226, thorium, and uranium) should be handled as greaterthan-Class III. With cooperation from a working group of representatives from each DOE disposal site, the DLLWMP drafted a revised Chapter III dated 
September 30, 1987, which was further revised at DOE-HQ on November 27, 1987.

The changes in the November 27, 1987, draft altered the September 30, 1987, Chapter III draft significantly. As changed, the classification system did not cover al1 radionuclides reported as significant by the major DOE waste disposal sites. Additionally, the November 27, 1987, draft omitted about $60 \%$ of the table from the September 30, 1987, version of Appendix A, "Waste classification Guidelines." Some of the radionuclides omitted included. uranium, thorium, and radium. The logic used for omitting the radionuclides was to make the table the same as the table in 10 CFR 61. This created problems for DOE sites using the table in Appendix $A$, because those radionuclides listed in the November 27, 1987, draft revision more closely represented waste streams from commercial reactors than those in DOE waste streams.

The major NRC concern with the proposed waste classification system was that the DOE dose limits were lower than those of the NRC, thereby putting two federal agencies in differing public positions. A potential path forward was to use the NRC limits to define operating guidance for DOE waste disposal, and still rely on the DOE performance objectives. The concerns raised by the NRC pointed out that incorporating the new dose models into the classification limits might be a very lengthy process, in view of the time constraints placed on the revision. Another argument given to defer hasty adoption of a DOE specific waste classification system was that it was thought to be internally inconsistent. For example, the lower limit for transuranics (TRU) calculated with the ICRP-48 parameters wouid not be the same as the TRU waste concentration limit of $100 \mathrm{nCi} / \mathrm{g}$.

Although there was much support for the establishment of a DOE waste classification system from a credibility standpoint, the system was not completed. The result was that sections in Chapter III of the proposed revision on waste classification were deleted, as was Appendix A, "Waste Ciassification Guidelines for Management of Low-Level Waste."

The NRC waste classification system was not adopted because (a) dissimilarities were found among waste forms, waste streams, and disposal methods between DOE sites, (b) DOE's proposed limits were more stringent than those of the NRC, in some cases, and (c) the basis of the NRC system was a generic disposal scenario.

A goal of the LLW classification system was to allow each disposal site the freedom to develop limits to radionuclide inventories and concentrations according to its own site-specific characteristics. This goal was achieved with the adoption of a performance objectives system based on a performance assessment, with site-specific environmental conditions and engineered disposal systems. 


\section{FOREWORD}

As requested by the Performance Assessment Task Team (PATT), the Radioactive Waste Technical Support Program (TSP) drafted this informal report entitled DOE LLW Classification Rationale. The first draft report was distributed to all members of the PATT, and to a few other individuals involved in the 1988 revision of DOE Order 5820.2, for review and comment.

comments were received from only four individuals. The comments ranged from editorial comments to comments dealing with subject content. Most of the comments were incorporated when accompanied by some sort of justification or references. Those comments that could not be verified by reference were not incorporated. However, all comments will be kept on file at the TSP for future reference.

This final draft report incorporates the comments that were considered appropriate. 


\section{BACKGROUND}

\section{Why a Waste Classification System was Needed}

The need to revise DOE Order 5820.2, "Radioactive Waste Management, " became evident in 1986 due to mounting criticism of the ability of the Department of Energy (DOE) to self-regulate. DOE Order 5820.2 was singled out as an example of a weak regulatory order when compared to the Nuclear Regulatory Commission's (NRC) 10 CFR 61. In addition, the DOE operators felt that the 1984 version of Chapter III, "Low-Level Waste," was iradequate for their needs.

In 1986 the Defense Low-Le'vel Waste Management Program (DLLWMP) began rewriting DOE Order 5820.2, Chapter III "Low-Level Waste." DOE-Headquarters (HQ) expanded this initiative and issued formal direction to rewrite the entire order.

In early 1987, DOE began research to establish a low-level radioactive waste (LLW) classification system. DOE set up a working group to draft a prescriptive or a performance objective-oriented revision of the LLW chapter of DOE Order 5820.2. The simplest option was to adopt the 10 CFR 61 classification system, based on concentration of indicator nuclides and specific concentration limits for troublesome species. August 1987 was the goal for completing a working draft of the revised LIW chapter.

Classifying wastes by degree of hazard is the mechanism that helps ensure that the overall performance objectives are met over the long term. It does this through the collective consideration of the technical requirements and controls established for near-surface radioactive waste disposal. To a waste generator, it establishes requirements on the form and content of waste and establishes how to treat and package particular wastes. To a waste disposal facility operator, it defines the requirements and controls used in the disposal of particular wastes.

In an informal note dated January 21 , 1988, the DOE-HQ revision coordinator wrote that the LLW working group agreed on the need for a waste classification system for two reasons; one practical, the other symbolic. "The practical reason was the need for a systematic way to identify the relatively small volumes of LLW that contain most of the radioactivity and that require engineered protection for disposal in a near-surface environment for control of long-term dose to the public. The symbolic reason was the advantage gained in credibility if the DOE LLW disposal systems had requirements equivalent to those of the NRC for disposal of commercial LLW.

a. E. L. Albenesius, DP-123, to G. H. Daty, DP-123, "LIW Classification System in 5820.2," January 21, 1988. 


\section{Options Considered for Waste Classification System}

DOE considered two options in revising Chapter III of DOE Order 5820.2: (a) adopt NRC's 10 CFR 61 waste classification system, or (b) establish an independent DOE prescriptive or performance objective waste classificationbased system.

\section{NRC's IC CFR 61 System}

The simplest option was to adopt NRC's 10 CFR 61 classification system, based on concentration of indicator nuclides and specific concentration limits for troublesome species. This was a potential problem because of the dissimilarities of waste mixtures between DOE sites. The DOE wastes are dominated by tritium, fuel processing, and reprocessing operations wastes. NRC's wastes are dominated by commercial reactor and medical wastes. NRC's Class $A, B$, and $C$ waste classifications roughly correspond to DOE's Class I, II, and III, respectively.

\section{Prescriptive and Performance Objective Systems}

A performance objective waste classification system differs from a prescriptive system in many ways.

Performance objectives. A system based on performance objectives requires more effort and time in development due to the many factors that must be considered in determining compliance. Performance objective requirements allow maximum flexibility in the application of new technology and innovative solutions to ensure the safe disposal of LLW. They would allow for consideration of site-specific conditions and variation in the design, operation, and characteristics of waste. However, it might not be clear how to design and operate a disposal facility to meet the general objectives.

Prescriptive Requirements. Prescriptive requirements are difficult to derive. Also, they require frequent revision as the type and form of wastes change and as technology advances. They tend to discourage use of new or creative solutions to waste disposal problems even though they might result in lower environmental impacts and monetary costs. Prescriptive requirements concentrate on the individual components of a disposal system and can establish particular classes of waste in recognition of differing hazard potentials.

The DLLWMP was interested in establishing Class I, II, and II I limits for intruder protection purposes only. Then each site would do a radiological performance assessment (RPA) and modify the overall disposal practices as

a. Steve Minkin, EG\&G, to J. Logan, EG\&G, "Suggested Approach to DOE LLW Classification System," SCM-3-87, March 3, 1987. 
necessary to get the RPA to show that its disposal practices would meet the performance objectives.

\section{DOE Approach to LLW Classification System}

The Idaho National Engineering Laboratory (INEL) hosted several meetings to discuss the approach DOE should take in developing a classification system for its low-level waste. " The consensus of the meetings was that DOE should follow the NRC's classification system in 10 CFR 61 as closely as possible. In adopting this system, DOE would modify the NRC waste classification system according to the DOE system approach, incorporating existing policy and special needs. Also, DOE would adopt an intruder approach. In addition, the DOE LLW classification system was to be cost effective, and reduce the burden placed on the waste disposal operator.

\section{WASTE CLASSIFICATION SYSTEM ISSUES}

There were several technical issues that needed to be addressed in order to establish a DOE waste classification system. The primary issues were differences in (a) radionuclides in DOE waste streams Vs. iNRC's commercial waste streams, (b) assumptions used for the migration of certain radionuclides through soil to groundwater, and (c) locations of disposal sites.

\section{Comparison of DOE and NRC LLW}

The DLLWMP collected information and issued a report on waste disposed of at the Radioactive Waste Management Complex (RWMC) at the INEL for 1971-1983." The purpose of the report was to compare DOE LLW to the LLW that the NRC considered for 10 CFR 61 .

of the 74 radionuclides 1 isted, many had half- 7 ives of less than two years and were considered inconsequential in the long-term impact of LLW disposal and were disregarded. Eight of the remaining 35 were transuranics, and were among those considered by the NRC. Five more radionuclides at the INEL were associated with the thorium fuel cycle and were not considered by the NRC in 10 CFR 61.

The NRC considered only 17 of the 22 remaining RWMC radionuclides. The status of the remaining five was not clear.

a. J. A. Logan, EG\&G, to E.A. Jennrich, EG\&G, "Defense Low-Level Waste Management Program, Scoping Evaluation of LLW Radionuclides Disposed at the INEL RWMC, 1971 through 1983," JAL-49-87, May 6, 1987. 


\section{Groundwater Issue}

In Apri7 1987, a proposed groundwater strategy for disposal of LLW was presented. ${ }^{\circ}$ Groundwater impacts are considerably more site-specific than concentration-limited intruder impacts. The total activity of disposed wastes are used to calculate groundwater impacts, rather than particular waste stream concentrations. In addition, the specific environmental conditions of the site, and the design and operation of the disposal facility, relate to groundwater impacts.

The NRC guideline for 1 and disposal of LLW permits limited contamination of groundwater beneath a disposal facility. The concentrations of radionuclides in a water well at the boundary of a disposal site must not permit an individual water user to exceed an annual dose of $25 \mathrm{mrem} / \mathrm{yr}$. Because of the critical issue of groundwater protection at humid sites, a performance objective for new DOE disposal facilities was that concentrations of radioactivity at the boundary should not exceed a dose of $25 \mathrm{mrem} / \mathrm{yr}$ to the whole body or a critical organ to a potential water user. The proposed point of compliance was set one meter downgradient from the edge of the disposal site boundary.

\section{Disposal Site Locations}

Comments on the groundwater contamination issue centered on groundwater protection, which applied at humid sites but did not apply at arid sites. In revising Chapter III, the LLW working group noted that there was more than one performance objective, one for humid sites and one for arid sites. There should be a unified set of performance objectives that apply to all DOE LLW disposal sites. NUREG-0782 states that rather than set concentration limits for radionuclides, a better approach would be to set inventory limits on a site- and facility-specific basis for nuclides important to groundwater migration.

\section{DOE STRATEGY TO ESTABLISH A LLW CLASSIFICATION SYSTEM}

\section{Goal of DOE LLW Classification System}

The goal was to formulate a $L L W$ classification system (similar to NRC) to allow each disposal site the freedom to determine a radionuclide inventory according to its own site-specific characteristics. The advantages of this system were (a) cost-effective site characterization vs. generic

a. Ed Albenesius, DOE, to J.E. Lytle, DOE, "Proposed Ground Water Protection Strategy for LLW Disposal," April 29, 1987.

b. Nuclear Regulatory Commission, Draft Environmental Impact Statement on 10 CFR 61, "Licensing Requirements for Land Disposal of Radioactive Waste," NUREG-0782, Volume 2, September 1981. 
modeling, and (b) more speciffc data for predicting long-term performance of each radionuclide. Also, site-specific inventory limits might permit DOE to dispose of more LLW in an arid site than NRC would allow according to a worst case scenario.

\section{Meeting Held to Discuss Options}

A meeting was held on May 7-8, 1987, to review the draft DOE approach to waste classification and to establish overall performance objectives. ${ }^{a}$ The performance objectives allowed for the protection of (a) workers and the public during site operation (consistent with other DOE orders), (b) intruders who may accidentally move onto a closed DOE. LLW disposal site after loss of institutional controls, (c) members of an offsite population group, and (d) water resources through the enforcement of applicable standards.

Calculations were outlined for intruder scenarios similar to those used by the NRC in establishing the 10 CFR 61 waste classification system. The calculations served to (a) check the assumptions used by the NRC in the intruder scenarios and compare them to DOE site and waste conditions, (b) check the accuracy of the NRC calculations for individual radionuclides, and (c) identify the potential numerical differences resulting from using the DOE performance objectives and effective dose equivalent factors.

\section{Time Constrai it Placed on Revision}

From the outset, a time constraint was placed on the revision of the order which eventually resulted in deferral of the proposed waste classification system. A strategy in coordinating the revision of the Order was to get a prescriptive, strong order issued near the goal of May 1988. The NRC pointed out that completion of the classification system by following the initial path, that is, incorporating the new dose models into the classification limits, might be a very lengthy process.

Several approaches were used to allow the order to proceed on schedule for issuance in May 1988. In the concurrence process, approval of the principle of a waste classification system was sought. Also sought was an approach that would put an operational objective onto the classification system. This would allow use of the NRC classification ranges for Class $B$ and $C$ waste simply to determine, as a minimum, which DOE wastes would need extra protection to qual ify for disposal. The dose-to-public control on this approach would come through the application of a site-specific, waste-specific performance assessment model. The details would be worked out in the implementation process.

a. W. E. Kennedy, Jr., W. T. Ferris, Draft U. S. Department of Energy LowLevel Waste Classification System, Pacific Northwest Laboratories Richland, WA, June 1987. 


\section{Differences Between DOE and NRC Classification Systems}

A distinct difference between the suggested DOE waste classification system and the NRC's was the use of site-specific models. The basis of the NRC system was a worst-case generic disposal scenario. In addition, NRC used ICRP-2, Radiation Protection, Report of Committee II On Permissible Dose of Internal Radiation, to determine waste classification; DOE used ICRP-26, -28 , -30 , and -48 for calculating internal dose factors.

\section{Suggested Approach to Development}

The DLLWMP suggested an approach to developing a DOE LLW classification system as follows (Minkin, p.6):

1. DOE should use an approach similar to NRC's in developing a LLW classification system

2. The DOE waste classification system should include five classes:

a. Below regulatory concern (BRC) threshold limits

b. Equivalents to NRC Classes $A, B$, and $C$

c. Greater confinement disposal (greater-than-Class C)

3. DOE should adopt International Commission on Radiation Protection (ICRP) methodology to determine waste classification (radionuclide concentration) limits

4. DOE should base waste classification limits on risk assessment for a given source term, including projected waste stream characteristics

5. DOE should determine waste classification limits using sitespecific performance models and parameters

6. DOE would provide guidance to each disposal site concerning radionuclide pathway scenarios.

\section{DOE Performance Objectives}

Kennedy and Ferris (see p.9) provided a summary of the calculated draft DOE waste classification limits and a comparison of the NRC Class A and C limits. In calculating the draft DOE limits, the same scenarios and assumptions identified by the NRC for 10 CFR 61 were used, with two exceptions: (a) use the DOE dose performance objectives of $100 \mathrm{mrem} / \mathrm{yr}$ effective dose equivalent (EDE) for continuous exposures and $500 \mathrm{mrem} / \mathrm{yr}$ EDE for short term exposures, and (b) use the DOE internal dose factors based on ICRP - 30. These changesaccounted for the majority of the differences between the DOE and NRC waste classification limits. 
Using the performance objectives above, the dominant scenario for the calculation of the draft DOE Class I and III limits was the intruder. agriculture scenario. Because of the reduced dose limit, the DOE Class I and III limits were more restrictive than the corresponding NRC limits. For transuranics, soil erosion also had a significant effect and caused further reductions in the calculated DOE waste classification limits.

\section{DEVELOPMENT OF A LLH CLASSIFICATION SYSTEM}

\section{Development Methodology}

The method used to draft the numerical values set for the proposed DOE LLW classification system was similar to NRC's methodology (Kennedy and Ferris, p.9). The DOE (a) reviewed and listed the scenarios, parameters, and assumptions used by the NRC in setting the Class $A$ and $C$ limits in 10 CFR 61 , (b) performed calculations for unit concentrations of selected radionuclides using the major parameter values and assumptions cited by the NRC with the DOE internal dose conversion factors (for compliance with the DOE performance objectives), and (c) performed an inverse-type calculation to set up the waste concentrations that would be permitted at the time of burtal so intruder dose performance objectives could be met at the assumed time of intrusion.

\section{NRC Intruder Scenarios}

The NRC considered three intruder scenarios that resulted in human exposure: (a) intruder-construction, (b) intruder-discovery, and (c) intruderagriculture. Scenarios a and $c$ (by radionuclide) set the Class $A$ and $C$ waste classification limits. Scenario b was used to set the Class $B$ limits. These scenarios are described by NUREG-0782 (see p.8) and by Oztunali and Roles.

\section{DOE Intruder Scenarios}

The potential DOE waste classification system intruder doses were estimated using the assumptions and parameters assigned by the NRC in their intruderconstruction and intruder-agriculture scenarios and using the proposed DOE performance objectives and internal dose conversion factors.

In calculating the draft DOE limits, the same scenarios and assumptions identified by the NRC for 10 CFR 61 were used with two exceptions. The exceptions were to use the DOE performance objectives and the DOE internal dose factors. These changes accounted for the majority of the differences

a. 0. 1. Oztunali, and G. W. Roles, Update of Part 61 Impacts Analysis Methodology, NUREG/CR-4370, Vol. 1, U. S. Nuclear Regulatory Commission, Washington, D.C., 1986. 
between the DOE and NRC waste classification limits. The NRC used special models for tritium and carbon-14 to account for their pathway behavior. Using the NRC performance objectives and dose factors, close agreement with the NRC values was obtained within a factor of 2 .

\section{Establ ishment of LL.W Working Group}

Some members of the LLW classification working group that was created favored a simple, external radiation-based waste classification system with "crude" nuclide limits inferred. Others favored adopting the NRC waste classification system. The consensus of the working group favored a more complex and sophisticated approach over either of the above. Given the time constraints of the schedule, they proposed using the NRC's methodology and adapting it to reflect two factors: (a) the mixture of wastes that DOE manages is different from the commercial wastes that the NRC regulates, and (b) DOE was adopting the new dose models of ICRP-30 and ICRP-48 along with the ICRP recommendation 10 limit the long-term effective dose to the public to 100 $\mathrm{mrem} / \mathrm{yr}$. The ICRP-2 dose model and a long-term public dose limit of 500 $\mathrm{mrem} / \mathrm{yr}$ are the basis for the NRC limits.

The working group decided to (a) have each site representative turn in a list of principal nuclides likely to appear in their LLW, (b) ask Pacific Northwest Laboratories (PNL) to put the ICRP-30 internal dose factors into the NRC INVERSE Code and determine upper limit values for LLW Classes I, II, and III, and (C) ask PNL to run the INVERSE Code with ICRP-30 input to develop upper limit values for the additional nuclides provided by the working group participants.

\section{Development of List of Radionuclides in DOE Waste}

The working group developed a list of 33 nuclides. The list was virtually the same as the list of nuclides in Oztunali and Roles (see p.11). The two lists were compared and it was determined that several of the long-lived fission products were minor constituents of a fission product mixture and should be discarded. In addition, 12 of the nuclides on the DOE list were naturally occurring alpha emitters included in LLW standards the Environmental Protection Agency (EPA) was developing.

It was felt that any DOE limits for the alpha emitters would be premature. Because of this concern, the list of nuclides was shortened to 12 in the draft that went forward in the concurrence process. A footnote was added to the table stating that additional nuclides may be added to the list during the implementation process. Further, it was felt that DOE LLW rontained basically the same nuclides as commercial LLW; it is the relative amounts of specific nuclides that was different.

During the effort to expand the list of nuclides and apply methodology with modifications, it was evident that the working group underestimated the complexity and difficulty of establishing a waste classification system. The results of the INVERSE run determined that DOE upper 1 imits were in many cases 
substantially lower than those of NRC's because of $5820.2 \mathrm{~A}$ objectives and ICRP-30.

Throughout the development process, the objective was to develop operational upper 7 imits for DOE waste categories. The real driver in chapter III was the requirement that each disposal site determine, via a performance model, what waste-specific and site-specific engineered amendments would be required to ensure that the waste disposal system would meet all the performance objectives. The waste classification limits have always been intended as operational limits useful as maxima to dide recisions on when and how to stabilize, durably package, or bury deek. watect "ins low-volume highactivity waste fraction against intrusion. would be approving the principle of a waste classifi cion sy limits. To delay the progress of this review on the bas paysting a DOE-specific wiste classification system would be a lengthy and asicaliy unproductive enterprise. It was suggested that it would be useful to fiave the INEL DLLWMP program begin to assume the lead in addressing the modeling required to implement the performance assessment model [Chapter III.3.b.(1)].

The final argument given to abandon hasty adoption of a DOE specific waste classification system was that the system was internally inconsistent. For example, the upper limit for LLW with TRU was left intact at $100 \mathrm{nCi} / \mathrm{g}$. The ICRP-48 parameters would lower it to the 20-30 nCi/g range. This would impact the certification system for TRU and the Waste Isolation Pilot Plant program.

A DLLWMP report stated that DOE had adopted ICRP-30 and ICRP-48 as the basis for all internal dose calculations. ${ }^{a}$ For LLW management, DOE was requiring equivilency with NRC requirements. However, system-wide classification would be less practical for DOE than for NRC because of dissimilarities of waste mixtures between DOE sites. They stated that site-specific waste stream characterization, source-term determination, and radiological performance assessment would be required at DOE disposal facilities to determine the maximum disposal capacity and the most efficient disposal practices for defense LLW.

\section{Review of Proposed Waste Classification Table}

DLLWMP sent a letter on October 15, 1987, to the various sites requesting review of the waste classification table in a draft revision of DOE Order 5820.2. ${ }^{\circ}$ Some reviewers felt that the table was too long and needed to be reduced.

a. D. K. Halford, DOE Defense Low-Level Waste Classification: Basis and Application, IAEA-SM-303/130, May 1988.

b. D. K. Halford, INEL, to Distribution, "Defense Low-Level Waste Management Program, Waste Classification Table in Revised DOE Order 5820.2 Chapter III," DKH-17-87, October 15, 1987. 
DOE-ID issued a memorandum of the response to comments on DOE Order 5820.2 , Chapter III, on October 19, 1987. ${ }^{\text {a }}$ In general, the comments on the waste classification table in Appendix A, Chapter III, were (a) the limits were too restrictive (and the basis for the derivation was missing), and (b) DOE should handle certain radionuclides (iodine-129, radium-226, thorium, and uranium) as greater than Class III.

Comment (b) was a concern because of the lack of sound information about the quantity of these wastes, but it was not pursued. Due to consideration of the concerns addressed, revised concentration limits were developed. The proposed response to comment (a) was to issue a guidance document.

\section{REVISED DRAFT OF CHAPTER III}

With cooperation from a working group of representatives from each DOE disposal site, the DLLWMP drafted a revised Chapter III dated September 30 , 1987, which was further revised at DOE-HQ on November 27, 1987. The DLLWMP received the November 27, 1987, draft of DOE Order 5820.2 Chapter III from DOE-HQ on December 11, 1987, for comment. "The changes made altered the Chapter III draft significantiy. As changed, the system did not cover all radionuclides reported as significant by the major DOE waste disposal sites.

The November 27, 1987, draft of Chapter III omitted about $60 \%$ of the table from the September 30, 1987, version of Appendix A, "Waste Classification Guidelines." Some of the radionuclides omitted included uranium, thorium, and radium. The logic used for omitting these was to make the tahle the same as that in 10 SFR 61. This created problems for DOE sites using the table because those radionuclides in the November 27, 1987, draft revision more closely represented waste streams from commercial reactors than those in DOE waste streams. In addition, guidance provided by the more extensive radionuclide 1 ist from the September 30, 1987, version was lacking in the November 27, 1987, version.

\section{Review and Comments on November 27, 1987, Draft}

The 1etter "Comments on Draft Order 5820.2 (Noveniber 27, 1987)" discussed potential problems with the revised (November 1987) waste classification

a. S. T. Hinschberger, DOE-ID, to Defense Low-Level Waste Issues Working Group, "Response to Comments on DOE Order 5820.2, Chapter III," October 19, 1987.

b. J. A. Logan, EG\&G, to S. T. Hinschberger, DOE-ID, "Defense Low-Leve1 Waste Management Program, Concerns with 11/27/87 Draft of DOE 5820.2 Chapter III," JAL-149-87, December 29, 1987. 
system. TwC approaches discussed to solve the problems were to fix the present system or to adopt the NRC system directly. ${ }^{a}$

The advantage of the classification system in the November $27,1987, \mathrm{dr}$. $\mathrm{ft}$ was that the system was derived from the DOE performance objectives using NRC methodology. However, the 1 imits calculated by PNL were considered preliminary and might contain errors. I was suggested that the discussion of the proposed classification system be amended to make it clear that the table of disposal limits in the appendix was provided for guidance only. In addition, it shoult be made clear that waste disposal is bound by the performance objectives discussed.

A major concern with the proposed waste classification system was that the DOE dose limits were lower than the NRC's. The NRC was concerned that lower DOE limits would force them to decrease their limits. A potential approach was to use the NRC limits to define operating guidance for DOE waste disposal, and still rely on the DOE performance objectives.

\section{Informal Discussion with NRC}

The DOE-HQ revision coordinator met with representatives of the $L L W$ Division of the NRC to discuss the LLW classification system in the revised draft of 5820.2. They discussed the similarities and differences of the DOE LLW classification system to NRC's 10 CFF 61 system. DOE's system incorporated the ICRP-30 dose model, a significant change in the DOE position on performance objectives compared to the NRC. The specific waste classification limits in the draft 5820.2 revision were lower than those of the NRC system-in some cases, substantially lower.

The differences that caused concern and questions from the NRC were:

1. Radically lowering DOE waste classification limits would cause NRC limits to be ratcheted downward by public pressure

2. The limits published in the draft Order might be unrealistically low (i.e., errors might have been made in applying NRC methodology; wrong transfer coefficients might have been used)

3. The draft. DOE limits had one serious internal inconsistency, in that the upper limit for LLW was accepted unchanged at

a. E. L. Wilhite and J. R. Cook, 773-43A, to E. L. Albenesius, DP-123, "Comments on Draft Order 5820.2 (November 27, 1987)," January 19, 1988.

b. E. L. Albenesius, DP-123, to G. H. Da7y, DP-123, "Informal Discussion on LLW Waste Classification System of Draft 5820.2 with NRC-LLW Technical Personnel on Jnuary 13, 1988," January 15, 1988. 
$100 \mathrm{nCi} / \mathrm{g}$ and not determined via the new dose model and public dose limit, which would have reduced the number substantially

4. The upper limit for Class $C$ waste in 10 CFR 61 became the legal limit for LLW under the control of NRC by the Nuclear Waste Policy Amendments Act of 1985.

\section{Concurrence process - Waste Classification System}

During the concurrence process comments were received from the various sites concerning the waste classification system. Some of the comments received were as follows: ${ }^{a}$

Office of Environment, Safety and Health (EH)

Recommend that a requirement for a uniform classification systein be abandoned. Recommended guidance:

1. Establish DOE-wide uniform criteria for performance objectives

2. Require performance assessment (PA) based on site-specific waste characterization and conditions

3. Require the development of implementation plans for each site with concurrence and oversight provided by Defense Programs and the Assistant Secretary for Environmental, Safety, arid Health.

\section{Richland Operations office}

With the PA requirements controlling the disposal of low-level waste, the existence of the classification system for LLW with the prescriptive segregation, waste form, and disposal requirements is not necessary. These types of requirements are best based upon site-specific performance assessments. This would result in a documented technical basis for the management of wastes.

\section{Naval Reactors}

The draft order contains a LLW classification scheme patterned after the NRC's classification scheme in 10 CFR 61. However, the proposed limits are much more stringent than NRC's. For example, the Timits for $6-14$ are over 1000 times more restrictive than 10 CFR 61 . No justification is provided for the decreased limits other than the fact that they were calculated with a new

a. Unsigned memo, "Concurrence Process - Department of Energy Order 5820.2A Waste Classification System," March 8, 1988. 
computer code. The technical validity of the code or its supporting assumptions is not discussed; hence, there is no basis for an informal judgement as to why the NRC limits are inadequate. The proposed limits would result in a significant volume of Naval Reactors program waste being classified as greater-than-Class III, or unsuitable for shallow-land burtal, even though similar waste from a commercial activity would be considered suitable for burial by NRC.

\section{Idaho Operations office}

The waste class limits are considerably more restrictive than their counterparts in 10 CFR 61 . This resulted from taking guidance from ICRP-26 and ICRP-30 instead of ICRP-2 (on which 10 CFR 61 is based) since ICRP-26 and -30 provide more recent and restrictive guidance. DOE's use of these more restrictive limits would put two faderal agencies (DOE \& NRC) in differing public positions as to public protection limits, and this could prove detrimental. It is recommended that this be reconsidered. The alternative option of abiding by the same limits as 10 CFR 61, where 10 CFR 61 provides limits, and deriving limits for DOE's additional radionuclides on a similar basis, has some attractions. One is that there would be no differing public position regarding public protection limits.

\section{Savannah River Operations Office}

A major concern is potential conflict with the NRC (10 CFR 61). Specifically, DOE will have lower limits than NRC causing concern regarding lack of consistency in Federal radioactive waste management guidelines. This approach is based on the existing classification system that is derived from DOE performance objectives.

\section{Chicago Operations office}

DOE waste class limits do not coincide with those found in 10 CFR 61. These reductions in the limits appear to be overly conservative and will be very costiy to the waste generator.

On the basis of widespread comments (such as these), the waste classification system was discarded.

\section{PROPOSED AND FINAL RESOLUTION OF COMMENTS ON $5820.2 \mathrm{~A}$}

In an informal note, the DOE-HQ revision coordinator discussed the comments from the Office of Environment, Safety, and Health (EH) and the proposed resolutions. " The EH comments in the section above were accepted: the "Waste Classification, Derivative Treatment for Disposal" Appendix was deleted, as

a. E. L. Albenesius, DP-123, to G. H. Da7y, DP-123, "Proposed Resolution of EH Comments on 5820.2A," March 22, 1988. 
were sections $3 d(3), 3 d(4), 3 i(2), 3 i(3)$, and $3 i(4)$. Sections $3 i(2), 3 i(3)$, and $3 i(4)$ would be replaced with the following:

3i(2) Engineered amendments (stabilization, packaging, burial depth, barriers) for specific waste types and for specific waste composttions (fisston products, induced radioactivity, uranium, thorium, radium) for each disposal site shall be developed through the performance assessment model [3b(1)]. In the course of this process, site-specific waste classification limits may be developed if operationally useful in determining how specific wastes should be managed.

$3 i(3) \quad$ An Oversight and Peer Review panel of DOE, contractor, and other specialists in performance assessments will be selected by Director of Defense Waste and Transportation Management (DP-12) with appropriate field office representatives. Through consultation and review, this panel shall ensure consistency and technical quality around the DOE complex in the development and application of performance assessment models that include site-specific geohydrology and waste composition.

$3 i(4)$ Disposition of waste designated as greater-than-Class C as defined in 10 CFR 61.55 must be handled as special case waste. Disposal systems for such waste must be justified by a specific performance assessment through the National Environmental Policy Act process and with concurrence of DP12 or Office of Nuclear Energy, Department NE-20.

\section{CONCLUSION}

Although there was much support for the establishment of a waste classification system from a credibility, and protection of public health and safety, standpoint, the system was not completed. Some of the reasons for deleting the system were inadequate time given for the revision; proposed waste class limits were considerably more restrictive than NRC's, thereby putting two federal agencies in differing public positions; underestimation of the complexity and difficulty in establishing a classification system; and the system was thought to be internally inconsistent. The result was that sections in Chapter III of the proposed revision on waste classification were deleted, as was Appendix A, "Waste Classification Guidelines for Management of Low-Level Waste." And, NRC's waste classification system was not adopted.

NRC's waste classification system was not adopted because (a) waste forms and disposal methods were dissimilar between DOE sites, (b) DOE's proposed limits were much more stringent than NRC's, and (c) the basis of the NRC system was a worst-case generic disposal scenario.

A goal of the LLW classification system was to allow each disposal site the freedom to develop limits to radionuclide inventories and concentrations 
according to its own site-specific characteristics. This goal was achieved with the adoption of a performance objectives system based on a performance assessment, with site-specific environmental conditions and engineered disposal systems. 

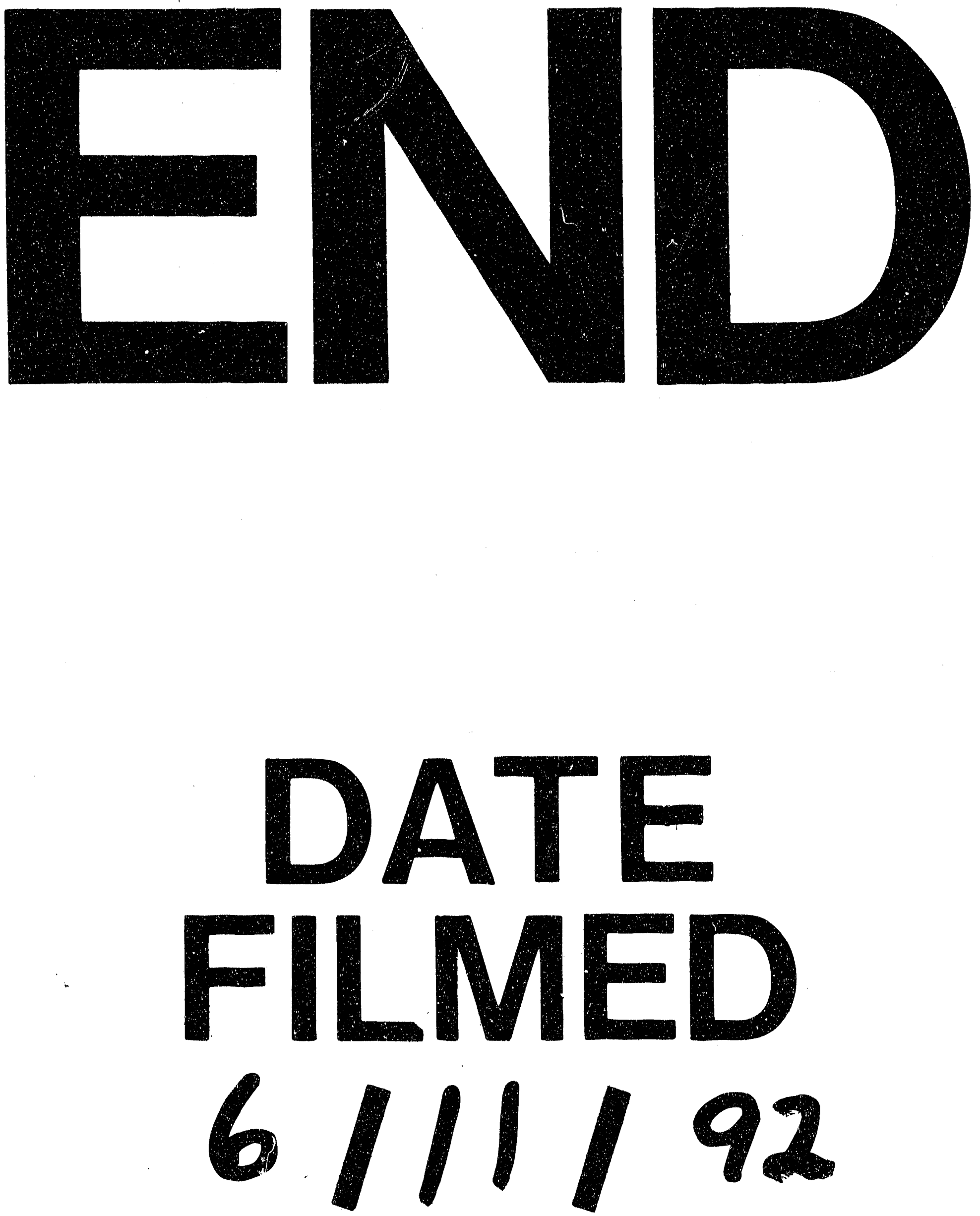
\ 